\title{
Relação entre espiritualidade e câncer: perspectiva do paciente*
}

\author{
Relationship between spirituality and cancer: patient's perspective \\ Relación entre espiritualidad y cáncer: perspetiva del paciente
}

\section{Giselle Patrícia Guerrero', Márcia Maria Fontão Zago", Namie Okino Sawada", Maria Helena Pinto' \\ 'Faculdade de Medicina de São José do Rio Preto. Departamento de Enfermagem Geral. São José do Rio Preto, SP \\ "Universidade de São Paulo. Escola de Enfermagem de Ribeirão Preto, Ribeirão Preto, SP}

Submissão: 06/10/2009

Aprovação: 16/05/2010

\section{RESUMO}

Objetivo: compreender a relação entre espiritualidade e o câncer na perspectiva de pacientes oncológicos. Método: estudo Qualitativo com participação de Quatorze pacientes com câncer em tratamento Quimioterápico e analisado segundo a análise de conteúdo temática indutiva. Resultados: os relatos foram organizados em três categorias: a descoberta do câncer, a fé como enfrentamento ao câncer, a busca pela cura do câncer. Compreendeu-se que o paciente oncológico busca a espiritualidade como forma de enfrentamento da doença, com a finalidade de minimizar o sofrimento ou obter maior esperança de cura com o tratamento. Consideração final: o tema central "o câncer amedronta e a espiritualidade renova" demonstra a importância do reconhecimento da espiritualidade como estratégia de enfrentamento no planejamento da assistência ao paciente oncológico.

Descritores: Espiritualidade; Cultura; Neoplasias; Cuidados de enfermagem.

\section{ABSTRACT}

Objective: to understand the relationship between spirituality and cancer under cancer patients' perspective. Method: Qualitative study, with the participating of fourteen cancer patients under chemotherapy treatment and analyzed according to inductive thematic content analysis. Results: reports were organized into three categories: cancer diagnosis, faith for coping to the cancer, the search for cancer cure. It was understood that cancer patients search spirituality as a way to cope with the disease, aiming to minimize their suffering or obtaining a higher hope of cure with treatment. Final consideration: the central theme "cancer frightens and spirituality renews" shows the importance of recognizing spirituality as a coping strategy in planning care to cancer patients.

Key words: Spirituality; Culture; Neoplasms; Nursing care.

\section{RESUMEN}

Objetivo: comprender la relación entre espiritualidad y cáncer en la perspectiva de pacientes oncológicos. Método: estudio cualitativo realizado con catorce pacientes con cáncer en Quimioterapia y analizado según el análisis de contenido temático inductivo. Resultados: los relatos fueron organizados en tres categorías: el descubrimiento del cáncer, la fe como enfrentamiento del cáncer, la búsqueda por la cura del cáncer. Se comprendió que el paciente oncológico busca la espiritualidad como forma de enfrentar la enfermedad, para minimizar el sufrimiento u obtener mayor esperanza de cura con el tratamiento. Consideración final: el tema central "el cáncer amedrenta y la espiritualidad renueva" demuestra la importancia de reconocer la espiritualidad como estrategia de enfrentamiento en la planificación de la atención al paciente oncológico.

Descriptores: Espiritualidad; Cultura; Neoplasias; Atención de enfermería.

*Trabalho de Conclusão de Curso da Graduação em Enfermagem, FAMERP, Trabalho de iniciação científica subvencionado pela FAPESP, processo no 2007/5523 I-6.

AUTOR Gisele Patrícia Guerrero. Rua MarQuês do Pombal, 478. CEP I 4080- 100. Ribeirão Preto, SP.

CORRESPONDENTE_E-mail: giguerrero@usp.br 


\section{INTRODUÇÃO}

De acordo com a Organização Mundial da Saúde (OMS), mais de $70 \%$ de todas as mortes de câncer ocorrem em países de baixa e média renda, onde os recursos disponíveis para prevenção, diagnóstico e tratamento são limitados ou inexistentes. Em 2005, 7,6 milhões de pessoas ou 13\% de todas as mortes foram ocasionadas pelo câncer. A OMS estima Que nove milhões de pessoas morrerão de câncer em 2015 e 1 1,4 milhões, em 2030(1).

No Brasil, o câncer é um grave problema de saúde pública, tanto em relação ao controle de casos registrados como atividades de prevenção, situação sócio-econômica e desigualdades regionais, além de ser considerada a segunda causa de morte no país. Segundo previsões do Instituto Nacional do Câncer (INCA), para os anos de 2010/201 I são estimados 489.270 casos novos de câncer, sendo esperados 236.240 em homens e 253.030 em mulheres ${ }^{(1-2)}$.

O câncer, na nossa sociedade, embora com as inúmeras formas de tratamento, ainda é considerado uma doença incurável, Que evidencia a proximidade da morte. Assim, os pacientes e os familiares, diante da desesperança e do sofrimento causado pela descoberta da doença, buscam na espiritualidade um sentido positivo ou negativo às experiências ${ }^{(3)}$. O cuidado ao paciente oncológico, com o significado atribuído ao câncer, torna-se mais complexo do Que outras doenças, pois envolve, além dos aspectos físico-biológicos e socioculturais, os aspectos espirituais das pessoas. Cabe ao enfermeiro, responsável pelo planejamento individualizado da assistência, compreender e valorizar a relação entre espiritualidade e o enfrentamento ao câncer, na visão do paciente ${ }^{(4)}$.

\section{REFERENCIAL TEÓRICO}

A cultura está organizada em um sistema simbólico e de significados compartilhados Que envolvem descrições minuciosas dentro de um contexto, no Qual as formas culturais encontram articulação no próprio comportamento e necessitam de interpretações para sua compreensão, além de considerar as particularidades vivenciadas por cada um na sua maneira de viver, ver e vivenciar o mundo ${ }^{(5)}$.

Para a Enfermagem, o conceito de cultura é necessário, pois o ser humano deve ser percebido em suas dinâmicas individual e social. Com base em alguns teóricos, cultura é conceituada como uma "teia de significados" Que o próprio homem tece; é dinâmica, e os indivíduos estão sempre reorganizando suas representações; ela também é pública, compartilhada, aprendida, lógica, coletiva e individual. Deve-se ressaltar a relação entre ação e representação, necessária para Que enfermeiros entendam como a cultura é gerada e Que, além de respeitar as práticas individuais, devem compreender as práticas culturais e os significados de espiritualidade e câncer ${ }^{(5)}$.

É necessário entender Que os termos "espiritualidade" e "religião" estão relacionados, mas, apesar de muitas vezes serem utilizados como sinônimos, esses conceitos não apresentam as mesmas características ${ }^{(6-7)}$. A espiritualidade é mais ampla e pessoal, está relacionada a um conjunto de valores íntimos, completude interior, harmonia, conexão com os outros; estimula um interesse pelos outros e por si; uma unidade com a vida, a natureza e o universo. É aquilo que dá sentido à vida, independente de sua religião, e, dessa maneira, produz capacidade de suportar sentimentos debilitantes de culpa, raiva e ansiedade; além disso, os aspectos espiritualistas podem mobilizar energias positivas e melhorar a Qualidade de vida das pessoas ${ }^{(4,6-7)}$.

Para alcançar o espiritual, uma pessoa não necessita pertencer a uma religião, ou seja, a um sistema de crenças organizado e compartilhado por um grupo e Que inclui a existência de uma força divina ou um ser superior, com propostas de normas, idéias e práticas (rituais) $)^{(4,6-7)}$.

Assim, o objetivo deste estudo foi compreender a relação da espiritualidade e o enfrentamento ao câncer na perspectiva dos pacientes oncológicos, com a finalidade de subsidiar o seu planejamento de cuidados.

\section{MÉTODOS}

Tratou-se de um estudo de abordagem metodológica Qualitativa, centralizado nas crenças e nas culturas humanas em relação a comportamentos de saúde, o Qual possibilitou maior compreensão da percepção do paciente oncológico com relação aos significados do seu processo saúde-doença e da assistência de enfermagem prestada.

O estudo foi desenvolvido no setor de Quimioterapia de um hospital público, referência na região noroeste do estado de São Paulo, onde são realizadas aproximadamente 440 sessões de Quimioterapia por mês. No registro do câncer da instituição há 8200 pacientes cadastrados desde o ano de 2000 , sendo em média 1500 casos novos por ano.

A entrada no campo se deu após aprovação do projeto de pesquisa pelo Comitê de Ética e Pesquisa da Faculdade de Medicina de São José do Rio Preto, com o parecer no 211 /2007.

Participaram da pesquisa 14 pacientes de ambos os sexos, maiores de 18 anos, cientes sobre o diagnóstico, estavam em tratamento Quimioterápico endovenoso e concordaram após orientação, ser sujeito da pesquisa com assinatura do termo de consentimento livre e esclarecido, conforme Resolução 196/96 do Conselho Nacional de Saúde (CNS) ${ }^{(8)}$.

$\mathrm{Na}$ coleta dos dados foi utilizado um gravador e um roteiro de entrevista com dados de identificação (sexo, idade, estado civil, religião e ocupação) e três perguntas abertas: Qual o significado de ser portador de câncer? Qual o significado de espiritualidade? Qual a relação entre a espiritualidade e o câncer? As entrevistas foram realizadas durante a sessão de Quimioterapia, em uma sala reservada, entre os meses de fevereiro e março de 2008, e os participantes foram identificados por números seguindo a ordem das entrevistas.

Após as várias leituras das entrevistas, os relatos foram condensados em texto com o intuito de propiciar a conexão entre os objetivos da pesquisa e a síntese dos resultados, seguindo os pressupostos da análise de conteúdo temática indutiva ${ }^{(9)}$. Assim, após a codificação indutiva e a apreensão de significados da espiritualidade e enfrentamento ao câncer, durante o processo de doença e tratamento, organizou-se os dados em três categorias temáticas: A descoberta do câncer; A fé para o enfrentamento ao câncer e A busca pela cura do câncer.

\section{RESULTADOS E DISCUSSÃO}

Em relação às características gerais da amostra estudada, nove 
eram do sexo feminino e cinco do sexo masculino, com idades entre 23 e 72 anos; nove casados, três viúvos e dois solteiros. A maioria dos pacientes reside com a família; sete deles eram aposentados, dois dependentes do auxílio-doença, dois do lar, um comerciante em atividade, um desempregado e um afastado do trabalho devido à doença. Entre os participantes, 13 relataram ser religioso; desses, sete são católicos e seis protestantes; apenas um negou seguir alguma religião. Seis relataram ser praticantes e oito disseram nem sempre praticar; desses, três buscaram com maior frequência os sistemas religiosos após a descoberta da doença, três diminuíram sua frequência devido a algumas dificuldades encontradas pela própria doença e um mudou de religião.

O tempo de diagnóstico médico do câncer variou de um mês a vinte anos, sendo estes: câncer de mama, sarcoma, leucemia, mieloma, câncer de cabeça e pescoço, colo do útero, intestino e fígado, além de alguns casos de metástases. Sobre o tratamento, seis pacientes haviam sido submetidos somente a Quimioterapia, cinco a cirurgia e a Quimioterapia, dois a cirurgia, radioterapia e Quimioterapia e apenas um a radioterapia e Quimioterapia.

Com relação às características sócio-demográficas, os dados mostram Que a doença pode ser manifestada e diagnosticada independente da classe social, da idade, da etnia ou grupos de forma igualitária(10)

A partir dos relatos dos entrevistados, apreendeu-se Que houve um processo desenvolvido entre a descoberta da doença até a esperança de possibilidade de cura e sobrevivência; cada indivíduo expressa sua espiritualidade relacionando-a à esperança de sobreviver ao câncer. Com a interpretação dos dados foi possível compreender Que $O$ câncer amedronta, e a espiritualidade Renova. Este foi o tema central interpretado nos dados obtidos pelos relatos dos pacientes.

\section{A descoberta do câncer}

No momento da descoberta do câncer, muitos entrevistados ficaram perplexos, alguns justificaram à sua forma de viver ou com acontecimentos passados, outros relataram Que QualQuer um pode desenvolver a doença; para a maioria, foi um choque, apresentando os sentidos dados à doença com os sentimentos de tristeza e indignação:

[...] foi chocante no momento da descoberta [...] (E I , feminino, 52 anos, casada, do lar)

[...] Quando soube Que tinha a doença, eu Quase morri [...] (E5, feminino, 69 anos, viúva, trabalhadora rural aposentada)

[...] deu muita tristeza na hora da descoberta [...] (E7, feminino, 42 anos, solteira, doméstica)

"Foi um susto Quando recebi a notícia Que estava com câncer" (E9, feminino, 50 anos, casada, comerciante).

Esses sentimentos de tristeza, indignação e angústia geralmente são decorrentes do significado do câncer, como uma doença estigmatizante, Que traz o sofrimento, Que é mantido no pensamento do paciente, e com isso o sentimento de medo perante a morte torna-se cada vez mais presente, em suas diversas fases, desde o diagnóstico até o tratamento. Esse tratamento pode proporcionar a cura ou a morte; de fato, não é possível ter controle ou previsão sobre isso. Esses sentimentos podem intensificar o sofrimento do paciente e até dificultar a possibilidade de seguirem adiante com seus projetos e ideais de vida, porém a tensão desses problemas poderá ser aliviada conforme as estratégias de enfrentamento, citadas em diversos estudos, como a força da fé e as crenças religiosas, ou seja, formas de expressar a espiritualidade encontradas por cada um ao lidar com a própria doença ${ }^{(1-12)}$.

Em contrapartida, foi possível observar relatos diferenciados com relação ao momento da descoberta do diagnóstico de câncer. Alguns pacientes referiram não apresentar reação ou QualQuer sentimento:

[...] não fiQuei muito assustado, não tive nenhuma reação, eu já sabia pela palavra do Senhor Que tinha câncer e não era para a morte [...] (E6, masculino, 66 anos, casado, agricultor, aposentado)

"recebi a noticia do câncer com calma, a família ficou mais apavorada do que eu" (EI2, feminino, 67 anos, viúva, aposentada)

Alguns pacientes, principalmente do sexo masculino, apresentam dificuldades em expressar seus sentimentos frente ao diagnóstico de câncer, com os relatos de Que nada sentiu, Que foi "normal". Isso pode indicar uma forma de autocontrole, de distanciamento dos sentimentos, de difícil compartilhamento dos medos e não preocupação com a própria saúde.

lá em um estudo com pacientes laringectomizados, apreendeuse Que o diagnóstico de câncer pode indicar uma sentença de morte, e a compreensão desse diagnóstico e sua terapêutica pode levar a uma transformação ou segunda chance de vida. Essa maneira de interpretar a doença grave constitui uma representação oriunda do senso comum entre diversos grupos sócio-culturais ${ }^{(13)}$.

Para alguns entrevistados, a origem da doença pode ser algo do próprio organismo, Que se altera conforme o estado emocional ou acontecimentos trágicos da vida, enQuanto outros afirmaram que o câncer é uma missão determinada por Deus:

[...] o câncer é um vulcão [...] "fica adormecido lá dentro por bastante tempo e depois solta às lavas e de repente destrói" (E9, feminino, 50 anos, casada, comerciante)

"Acho que é algo genético e hormonal que desencadeou a doença" (EI0, feminino, 62 anos, casada, professora aposentada)

[...] a doença forma na gente através das coisas que a gente passa, através de um sofrimento, um desespero, alguma coisa, penso que a gente deve ter algum distúrbio, algo emocional e acaba gerando a doença [...] (E5, feminino, 69 anos, viúva, trabalhadora rural aposentada)

[...] acho que é uma missão que nós temos que cumprir aqui, cada um vai passar a sua parte [...] (E3, masculino, 72 anos, casado, aposentado) 
O câncer ou neoplasia maligna ainda é considerado pela maioria das pessoas uma doença incurável e com difícil aceitação por todos; além disso, traz consigo vários significados e, na maioria deles, negativos. Talvez por isso, muitas pessoas tentam amenizar ou enfrentar essa situação de outra forma, ou melhor, procuram algo positivo para explicar tal doença e por vezes encaram-na como se fosse uma missão de vida ${ }^{(14)}$.

Observa-se Que o câncer foi comparado a uma missão, nesse caso, a doença é vista como um dever ou incumbência a ser passada em nome de um Ser Superior, ou com um objetivo maior além do sofrimento ocasionado pela doença:

"Não tive nenhum motivo de tristeza, porQue o Senhor falou pela palavra Que esta enfermidade pode ser um câncer, mas não é para morte é para uma glória em nome de Deus" (E6, masculino, 66 anos, casado, agricultor, aposentado)

"Essas coisas é Deus que está medindo a paciência da gente" (E7, feminino, 42 anos, solteira, doméstica);

"[...] cada ser humano vem aqui para cumprir uma missão [...] cada um tem a sua, uns com enfermidades difíceis de serem curadas [...] cada um tem um problema". (E3, masculino, 72 anos, casado, aposentado)

[...] Deus é nosso poderoso, Ele nos enviou aqui e estamos sob o comando Dele [...] (E3, masculino, 72 anos, casado, aposentado).

O câncer é uma doença Que traz diversos significados e símbolos, por isso é considerada uma doença metafórica, está relacionado às idéias de desordem, perigo, mal, castigo, fatalidade, entre outras, porém cada significado terá um sentido próprio conforme sua interpretação, a Qual é aprendida no meio cultural em Que se vive ${ }^{(14-15)}$.

A metáfora observada nesse estudo, "O câncer é um vulcão [...] Que solta sua lavas e causa a destruição", vem ao encontro de outras descrições encontradas na literatura, como o símbolo de caranguejo para o câncer, pois "vive em profundidade, invisível e se desloca mal coordenado e imprevisível; é agressivo, apodera-se de suas presas e as tortura até à morte", além de outras analogias como: "o câncer é como um formigueiro (...) se chutarem o formigueiro ninguém segura”, "É um dragão Que te devora”, "É como uma erva daninha Que rasteia, aí não tem jeito não!”(16).

Os relatos:

[...] Quando descobri Que era câncer, eu me desesperei [...] eu não Queria morrer, tinha meu caçula, não Queria deixar ele tão pequeno. (EI0, feminino, 62 anos, casada, professora aposentada);

[...] é uma doença Que pode levar à morte [...] " (E I 2, feminino, 67 anos, viúva, aposentada); "Eu sei Que o sarcoma é muito agressivo, é muito forte e tem risco de morte [...] (El4, masculino, 52 anos, técnico em informática).

Aassim como outros estudos, apontam que o sofrimento do luto está presente na própria existência do paciente oncológico ${ }^{(12,16)}$.
Durante todo o processo da doença oncológica, o paciente pode apresentar as distintas fases, Que são apresentadas diante da morte: negação, raiva, barganha, depressão e aceitação(1 ${ }^{(1)}$.

Vários são os significados para o sofrimento, algumas crenças relacionam a doença a um teste do indivíduo segundo a própria fé, ou um exemplo de paciência, restituição ${ }^{(4)}$. O câncer pode indicar uma sentença de morte, e a terapêutica pode levar a uma transformação ou segunda chance de vidaa ${ }^{(13)}$. Essas são formas Que os pacientes encontraram de significar e organizar o caos das suas vidas, são os padrões culturais da maioria das pessoas acometidas pelo câncer. A cultura modela os indivíduos como espécie única, mas, também, como indivíduos únicos ${ }^{(4-5)}$.

\section{A fé e o enfrentamento ao câncer}

Ao interrogar os pacientes sobre a relação entre o câncer e a espiritualidade, muitos entrevistados relataram primeiramente a fé, a crença em Deus, a importância da religião e inclusive sobre o pensamento positivo:

"Acreditar em Deus ajudou em tudo, no tratamento, na mente, porque você nunca pode pensar o mal, temos Que pensar positivo sempre." (E3, masculino, 72 anos, casado, aposentado)

“A religião traz coisa boa [...] se não fosse Deus, a gente não estava nem viva mais [...] eu confio!" (E4, feminino, 65 anos, casada, trabalhadora rural aposentada)

"Eu tenho muita fé [...] viva Que gera dentro de mim". (E5, feminino, 69 anos, viúva, trabalhadora rural aposentada)

"Ir para congregação ajuda a criar mais fé, mais coragem e otimismo". (E6, masculino, 66 anos, casado, agricultor aposentado)

Se você não tem fé, você perde a razão de viver [...] (E9, feminino, 50 anos, casada, comerciante).

Trentini et $\mathrm{al}^{(17)}$ relatam Que uma das formas de enfrentamento da doença e da morte está diretamente ligada à força da fé e a crenças religiosas; ou seja, formas de expressar a espiritualidade. Para pessoas idosas em condições crônicas de saúde, uma das formas de enfrentamento de situações adversas e favoráveis está no sentimento de fé em Deus. A fé em Deus é um sentimento arraigado na nossa cultura e é tão necessária Quanto são outros modos de enfrentamento; o discurso mostra Que a dimensão espiritual ocupa um lugar de destaque na vida das pessoas e mostra também que é imprescindível conhecer a espiritualidade dos usuários ao planejar o cuidado de enfermagem.

Os pacientes oncológicos passam por distintos períodos desde a descoberta até o tratamento do câncer: no primeiro momento, passam por um estado de choque, depois percebem que o que está acontecendo é real, e não sabem o Que pensar, posteriormente, começam a planejar o futuro com esperança. Dessa forma, é necessário considerar a dimensão espiritual do paciente para abordar a esperança e o enfrentamento da doença no planejamento da assistência, e, para isso, é fundamental conhecer a visão de mundo e a cultura à Qual ele pertence ${ }^{(18)}$. 
Ainda em outro estudo Que trata da religião e da espiritualidade como importantes fontes de apoio para o enfrentamento da doença crônica pelos familiares, as autoras relatam a influência desses recursos no comportamento dos familiares, cuidadores de crianças com insuficiência renal crônica, gerando sentimentos de esperança ou de aceitação frente às dificuldades ao lidarem com a doença crônica; além disso, os familiares mudaram a forma de perceber a vida e procuraram valorizar o presente. Assim, caso a aplicação dessas fontes de apoio permaneçam saudáveis, o enfermeiro poderá fortalecer esse mecanismo de enfrentamento ${ }^{(19)}$.

Dessa forma, a espiritualidade é uma expressão da identidade e o propósito da vida de cada um mediante a própria história, experiências e aspirações. $\mathrm{O}$ alívio do sofrimento acontece na medida em Que a fé religiosa permite transformações na perspectiva pela Qual o paciente e a comunidade percebem a doença grave ${ }^{(13)}$.

\section{A busca pela cura do câncer}

Os dados apontam Que muitos são aqueles Que, independentemente de sua religião, buscam a cura na fé, na crença em Deus e na esperança de um milagre:

"Quando soube da doença, eu Quase morri [...] procurei a igreja e pedi para entrar no Apostolado da Oração, Queria cuidar mais das coisas de Deus, porque eu Queria sarar [...]" (E5, feminino, 69 anos, viúva, trabalhadora rural aposentada)

[...] Deus, se Quiser faz um milagre sozinho, Ele faz, mas nós temos que acreditar nos médicos [...] (E8, masculino, 66 anos, casado, aposentado)

"Graças a Deus deu tudo certo, Deus me encaminhou para os melhores médicos, e a minha autoconfiança foi aumentando; à medida que o tempo passava, eu vencia todas as batalhas, com a graça de Deus sempre". (EI0, feminino, 62 anos, casada, professora aposentada)

"Morrer todos nós vamos [...] mas estou confiante em Deus Que vou sair dessa". (E 12, feminino, 67 anos, viúva, aposentada)

[...] Deus põe e Deus tira, Ele tem poder para tirar, então a gente apela com Ele e vai ao médico também". (E I3, feminino, 60 anos, viúva, do lar)

[...] eu sei Que precisa da mão de Deus para ajudar a me livrar dessa doença e usar os médicos para isto". (E6, masculino, 66 anos, casado, agricultor aposentado)

Alguns relatos apresentam de forma direta total confiança em Deus na busca pela cura: "Deus, se Quiser, faz um milagre", "Deus põe e Deus tira", "precisa da mão de Deus". Observa-se Que, após o sofrimento causado pela doença, ocorre uma maior conexão com a religiosidade e a espiritualidade, e esses pacientes conferem "a cura da doença à vontade de Deus", ou seja, expressam a esperança de cura com a intercessão do divino.

O apoio em Deus também já foi descrito na literatura como uma necessidade de auxílio espiritual para melhor enfrentamento do medo, da solidão e do inesperado. Em um estudo Que aborda os significados do câncer no cotidiano de mulheres em tratamento Quimioterápico, foi revelada a luta dessas mulheres pela própria vida, e essa luta sustenta a esperança em seu dia a dia; além disso, verificou-se que a origem da fé ocorreu pela descoberta da doença, assim, essa confiança em Deus pode ser percebida como uma forma de defesa aos sentimentos de temor e angústia(20).

Aceitar as situações Que desorganizam a vida e a submissão a Deus faz com Que o profano se submeta ao sagrado e, dessa forma, há o domínio da entidade divina sobre a vida dos homens. Assim, os acontecimentos imprevisíveis, como a doença, tornam-se previstos, o acaso é explicado, a segurança dada pela providência divina substitui a fatalidade.

Isso são formas de ver e enfrentar as diversidades da vida. Assim, observa-se Que a abordagem do câncer envolve sentimentos Que são difíceis de ser manejados pelos pacientes e pelas pessoas em geral. Na perspectiva do paciente, a cura do câncer ainda não está incorporada no repertório cultural como realidade, por isso é concebida como um milagre e não como um fenômeno possível de ocorrer, mesmo com os avanços da terapêutica médica ${ }^{(18)}$.

É importante ressaltar Que o paciente reconhece Que tem o direito de buscar alternativas para o seu próprio bem, mas elas não devem interferir em seu tratamento médico, mesmo Que a associação da medicina e de práticas espiritualistas tenham demonstrado refletir positivamente no bem-estar físico e mental durante todo o processo saúde-doença de um ser humano ${ }^{(21)}$.

[...] não é aquele negócio, vou na igreja, não vou tomar nada e sarar, não podemos deixar o tratamento, temos que pedir a Deus que o remédio faça o efeito desejado". (E9, feminino, 50 anos, casada, comerciante)

[...] eu sei Que precisa da mão de Deus para ajudar a me livrar dessa doença e usar os médicos para isto". (E6, masculino, 66 anos, casado, agricultor aposentado)

[...] os médicos sabem o Que preciso; estou sentindo uma boa melhora, graças a Deus, devido esse tratamento me sinto bem melhor". (E8, masculino, 66 anos, casado, aposentado)

"Graças a Deus meu oncologista é maravilhoso, [...] ele me dá as armas para eu ir para a guerra, e vou com tudo e venço". (E 10, feminino, 62 anos, casada, professora aposentada).

Estudos internacionais têm discutido e apresentado resultados significativos sobre a relação entre a espiritualidade, religiosidade, bem-estar físico e emocional e Qualidade de vida, com apresentação da necessidade de inclusão desses temas para melhor compreensão da integração da mente, corpo e espírito nos cuidados oncológicos, principalmente Quando se trata de mecanismos de enfrentamento da doença e do sofrimento ${ }^{(22)}$.

Além disso, outros estudos relatam a necessidade de oferta do suporte existencial, já Que alguns pacientes afirmam maior confiança devido à própria fé e referem melhorar a capacidade para adaptarse a novas situações; porém, os autores relatam alguns obstáculos para executar um suporte existencial adequado, como a falta de tempo para um diálogo prolongado entre a equipe de saúde e o paciente e dificuldades para identificar as reais necessidades do 
próprio paciente ${ }^{(23)}$.

Um elemento essencial para a prática de enfermagem e para a avaliação das necessidades culturais depende de uma comunicação eficaz com todos os pacientes e seus familiares, assim, cuidado culturalmente competente significa ser sensível ao contexto das seguintes perguntas: "O Quê?", "Quando?" e "Como?", além, claro, respeitar a forma como os próprios pacientes desejam ser chamados. Durante a interação com os pacientes, é importante saber escutálos ativamente, observar a linguagem corporal, ouvir o que eles estão dizendo e não tanto como estão dizendo; dessa maneira, será possível reconhecer as necessidades da dimensão cultural dos pacientes e familiares ${ }^{(24)}$.

Assim, compreende-se Que a relação entre a espiritualidade e o câncer na perspectiva do paciente é sintetizada pelo tema central: $O$ câncer amedronta e a espiritualidade renova. Embora tenha ocorrido uma evolução com relação ao tratamento oncológico, foi possível perceber, nesse estudo, Que o câncer ainda carrega o estigma do sofrimento, da angústia, da indignação e do medo frente às incertezas do futuro; porém, muitas vezes, tais significados, construídos na vida social e pela forma particular de interpretar tais acontecimentos, levam esses pacientes ao enfrentamento desse medo e assim produzem uma força intrínseca gerada, principalmente, pela vontade de viver e, dessa forma, proporcionam não somente um significado ao câncer ou à sua origem, mas sim um real significado à própria vida, sendo capazes de renovarem-se diante de transformações complexas em sua existência.

\section{CONSIDERAÇÕES FINAIS}

Com este estudo, foi possível compreender os significados de espiritualidade no enfrentamento ao câncer e a relação entre ambos, considerando a percepção individual dos pacientes e sua maneira de interpretar a espiritualidade, já Que se trata de um tema subjetivo e amplo. Foi possível identificar as reações dos pacientes no momento da notícia do diagnóstico e o significado da descoberta do câncer; posteriormente, foi descrito o enfrentamento ao câncer, ou seja, a forma com Que cada paciente oncológico encontra para enfrentar uma situação adversa como essa; por fim, observamos o envolvimento de cada um em relação à busca pela cura do câncer, seja de forma desesperada, mas sempre com intermédio de sua crença, religião, fé e esperança de um milagre e no poder do tratamento médico.

Os resultados demonstraram Que a espiritualidade pode ser uma forma de estratégia de enfrentamento do paciente perante o câncer, já que o próprio paciente poderá atribuir significado ao seu processo saúde-doença, em busca da sobrevivência e com apego à fé, para minimizar o seu sofrimento ou obter maior esperança de cura durante o tratamento, enfrentamentos estes adQuiridos na vida social.

A importância do reconhecimento da espiritualidade como estratégia de enfrentamento e a identificação das carências espirituais do paciente fazem com Que o profissional de enfermagem possa planejar e fornecer uma assistência da forma mais integral possível.

Espera-se que este estudo possa instigar o desejo de novas pesQuisas não só com relação à espiritualidade, mas também à reflexão individual sobre tal assunto, com a finalidade de relacionar a Qualidade de vida dos pacientes da oncologia Que se encontram nem sempre em busca da cura, mas em busca do bem-estar ideal.

Vale ressaltar que nosso estudo envolve um número pequeno de pacientes oncológicos e de maneira alguma esta é uma compreensão definitiva sobre a relação espiritualidade e câncer, pois a realidade sócio-cultural é dinâmica e multidimensional, o Que nos restringe a abordá-la sempre parcialmente e de modo superável no espaço e no tempo.

\section{REFERÊNCIAS}

I. World Health Organization. Cancer. Programmes and projects, Cancer; Data and statistics. Geneva: WHO; 2009. [cited 2007 Mar 25]. Available from: http://www.who.int/cancer/en/

2. Ministério da Saúde (BR). Instituto Nacional de Câncer. Estimativa 2010, Incidência do Câncer no Brasil. Rio de Janeiro; 2010. [citado em: 2010 Jun 5]. Disponível em: http:// www.inca.gov.br/estimativa/2010/

3. Koenig HG. Religion and medicine III: developing a theoretical model. Int I Psychiatry Med 200 I;3 I (2): 199-2 I 6.

4. Bruscagin C. Família e religião. In: Cerveny CMO. Família, comunicação, divórcio, mudança, resiliência, deficiência, lei, bioética, doença, religião e drogadição. São Paulo: Casa do Psicólogo; 2004. p. 163-86.

5. Geertz C. A interpretação das culturas. Rio de Janeiro: Livros Técnicos e Científicos; 1989.

6. Saad M, Masiero D, Battistella LR. Espiritualidade baseada em evidências. Acta Fisiátrica 2001; 8(3): 107-12.

7. Guimarães HP, Avezum A. O impacto da espiritualidade na saúde física. Rev Psiquiatr Clín 2007; (supl I): 88-94.

8. Ministério da Saúde (BR). Conselho Nacional de Saúde. Resolução 196/96. In: Ministério da Saúde (BR). Conselho Nacional de Ética em Pesquisa. Normas para pesquisa em seres humanos. Brasília: Ministério da Saúde; 2000. p. 22-46.

9. Elo $\mathrm{S}$, Kyngãs $\mathrm{H}$. The Qualitative content anaysis process. I Adv Nurs 2008; 62(1): 107-15.

10. Barton-Burke M, Barreto Ir RC, Archibald LIS. Suffering as a multicultural cancer experience. Semin Oncol Nurs 2008; 24(4): 229-36.

11. Borges ADVS, Silva EF, Toniollo PB, Mazer SM, Valle ERM, Santos MA. Percepção da morte pelo paciente oncológico ao longo do desenvolvimento. Psicol Estud 2006; I I (2): 36 I-9.

12. Carvalho MVB, Merighi MAB. O cuidar no processo de morrer na percepção de mulheres com câncer: uma atitude fenomenológica. Rev Latino-am Enfermagem 2005; 13(6): 951-9.

13. Aquino VV, Zago MMF. O significado das crenças religiosas para em grupo de pacientes oncológicos em reabilitação. Rev Latino-am Enfermagem 2007; 15(1): 42-7.

14. Tavares ISC, Trad LAB. Metáforas e significados do câncer de mama na perspectiva de cinco famílias afetadas. Cad Saúde Pública 2005; 2 I (2): 426-35.

15. Trincaus MR, Corrêa AK. A dualidade vida-morte na vivência dos pacientes com metástase. Rev Esc Enferm USP 2007; 4I(I): 44-5I. 
16. Dóro MP, Pasquini R, Medeiros CR, Bitencourt MA, Moura GL. O câncer e sua representação simbólica. Psicol Ciênc Prof 2004; 24(2): 120-33.

17. Trentini M, Silva SH, Valle ML, Hammerschmidt KSA. Enfrentamento de situações adversas e favoráveis por pessoas idosas em condições crônicas de saúde. Rev Latino-am Enfermagem 2005; 13(1): 38-45.

18. Pinto MH. O significado do sofrimento do paciente oncológico: narrativas dos profissionais de saúde [tese]. Ribeirão Preto: Escola de Enfermagem de Ribeirão Preto, Universidade de São Paulo; 2003.

19. Paula ES, Nascimento LC, Rocha SMM. Religião e espiritualidade: experiência de famílias de crianças com Insuficiência Renal Crônica. Rev Bras Enferm 2009; 62(1): 100-6.

20. Sales CA, Molina MAS. O significado do câncer no cotidiano de mulheres em tratamento Quimioterápico. Rev Bras Enferm 2004; 57(6): 720-3.

21. Faria JB, Seidl EMF. Religiosidade e enfrentamento em contextos de saúde e doença: revisão da literatura. Psicol Reflex Crit 2005; 18(3): 381-9.

22. Mytko II, Knight SI. Body, mind and spirit: towards the integration of religiosity and spirituality in cancer Quality of life research. Psychooncology 1999; 8: 439-50.

23. Westman B, Bergenmar M, Andersson L. Life, illness and death: existential reflections of a Swedish sample of patients who have undergone curative treatment for breast or prostatic cancer. Eur J Oncol Nurs 2006; 10: 169-76.

24. Allen S, Crouch A. Cultural and spiritual health assessment. Vital Notes for Nurses: Health Assessment 2005; 10: 311 30. 